\title{
ARASTTIRMA RESEARCH
}

\section{Seks Nedenleri Ölçeği'nin (YSEX?) Türkçe Uyarlamasının Güvenirliği ve Geçerliği Reliability and Validity of Turkish Version of Why Have Sex? (YSEX?) Questionnaire}

\author{
Sevilay Özcan, Hüseyin Güleç, Jülide Güler, Lut Tamam, Ayçe Soydan
}

\begin{abstract}
$\ddot{0 z}$
Bu çalışmada Meston ve Buss tarafından geliştirilmiş olan 142 maddelik Seks Nedenleri Ölçeği'nin (YSEX?) Türkçe uyarlamasının güvenirliği, faktöriyel yapısı ve geçerliği çalışıldı. Bu ölçek cinsel motivasyonların belirlenmesi amacıyla 237 sorunun değerlendirmesi sonrasında geliştirilmiştir. Bu çalışma Adana ve İstanbul ilinde yaşayan 401 sağlıklı gönüllü ile yürütüldü. Katılımcılara YSEX? ile birlikte ayrıntılı cinsel öyküyü de içeren sosyodemografik kayıt formu ve ayrıca uyarlanmış Eysenk Kişilik Anketi (EKA-GGK) verildi. Ölçeğin iç tutarlık incelenmesinde Cronbach alfa değeri 0.97 olarak bulundu. Sorular tek tek ele alındığında madde toplam ilişkisinin iyi düzeyde olduğu saptandı. Geçerlik analizinde, faktöriyel yapısına bakıldı. Açımlayııı Faktör Analizi'ne göre orijinal çalışmayla uyumlu olarak dört faktör altında toplandığı görüldü. Ölçüt bağıntılı geçerliği için EGA-GKK ölçeği ile yeterli düzeyde bağıntılı olduğu bulundu. YSEX?'in iç tutarlık, madde toplam ilişkisi, faktöriyel yapısı ve ölçüt bağıntılı geçerlik bulguları bu ölçeğin Türk örneklem kullanımında istatistiksel olarak geçerli ve güvenilir olduğunu göstermektedir.
\end{abstract}

Anahtar sözcükler: Seks Nedenleri Ölçeği (YSEX?), faktör analizi, geçerlik, güvenirlik.

\begin{abstract}
The aim of this study was to evaluate factorial analysis, reliability and validity of the Scale of Turkish version of the Why Have Sex Questionnaire (YSEX?) which has been developed by Meston and Buss. The study was carried out with 401 healthy participants who live in the city of Adana and Istanbul. Very good correlation level was obtained for the item-total score. The scale also showed very good internal consistency (Cronbach's alpha: 0.97). According to Explanatory Factorial Analysis four large factors was yielded. Criterion related validity of YSEX? was shown with significant correlation between Eysenk Personality Questionnaire Revised-Abbreviated (EPQ- RA). Internal reliability, itemtotal correlation, factorial analysis and criterion related validity of the YSEX? indicated that the scale has acceptable reliability and validity for the Turkish population.
\end{abstract}

Key words: Why have sex? (YSEX?) questionnaire, factor analysis, reliability, validity.

TOPLUM içinde cinselliğin sürekli önemli olduğu hakkında fikir birliği kabul edilse de konunun fark edilir oranda ihmal ettiği görülmektedir. Günlük konuşmalarda ve ilişkilerdeki öneminin yanı sıra cinsel ilişkinin hem etkilenen hem de etkileyen özelliği kabul görmektedir. Cinsel yakınlaşmaların toplumsal yükü birey için daha çok bilinçli olmayan biçimde baskı verici boyuttadır. Bilinçlilik düzeyindeki cinsel yakınlaşmalar da 
doğrudan elde etme şeklinde olmayıp, dolaylı veya bir sorun varlığında ortaya çıkmaktadir.

Tarihsel olarak bakıldığında insanların seks yapma nedenleri olarak az sayıda ve basit biçimde- çoğalmak, haz yaşamak veya cinsel gerilimi azaltmak- şeklindedir. Bazı kuramsal bakış açıları göstermiştir ki seks nedenleri sayısal olarak daha fazladır ve yapı olarak da daha karmaşık olabilir. Bu konudaki araştırmalar bakıldığında az sayıda çalışmaların varlığı görülmektedir. Bu çalışmalardan biri olarak Leigh (1989), seks için yedi neden tanımlamıştır; saf haz, duygusal yakınlık ifadesi, üreme, eş (partner) istediği için, eşini memnun etme, fethetme, cinsel gerilimi azaltma. Hill ve Preston (1996) ise yapisal cinsel güdülenme (motives) kuramsal bakış açısından etkilenmiş ve buna göre de sekiz neden bildirmiştir; eş tarafindan değer verildiğini hissetme, eşe değer verdiğini gösterme, cinsel gerilimden (stresten) kurtulma, eşini yetiştirme (nurturing), kişisel güç hissini arttırma, eşinin gücünü hissetme, haz yaşama ve üreme.

Seks nedenleri ile ilişkili nedenler, daha önceki çalışmaların gösterdiğinden daha karmaşık yapıda olabilir. "Fethetme" dışında yukarıda bildirilen çoğu neden uzun süreli romantik veya eş ilişkisinin var olduğunu varsaymaktadır. Cinsel taktikler kuramı (Buss ve Schmitt 1993) ve taktiksel çoğulluk (pluralism) kuramı (Gangestad ve Simpson 2000) insanların eşleşme menüsüne sahip olduğunu iddia etmektedir ve bunun uzun süreli, kısa süreli, eş olmadan olan ilişkiyi kapsamakta olduğunu ileri sürmektedir. Bununla birlikte cinsel çeşitlilik yaşama isteği (Symons 1979), birinin cinsel becerilerini arttırma isteği (Greiling ve Buss 2000) gibi farklı nedenler de olabilir ve bunlar devam eden bir romantik ilişki bağlamındaki nedenlerden farklıdır. Süren bir çift ilişkisi kapsamında dahi bu tanımlananların dışında birçok neden olabilir. Örneğin cinsel eşini ödüllendirme veya yaptığı bir şeyin karşılığı olma amacını güdebilir. İlişki içindeki bazı saygisızlıklar nedeniyle eşinden intikam almak için misilleme ilişkiye girme durumunda olduğu gibi cinsel eşini cezalandırmak için de kullanılabilir (Greiling ve Buss 2000). Aynı zamanda, devam eden bir ilişkide, ilişkinin yoğunluğunu ve bağlılığını arttırmak veya ilişkiyi daha uzun süreli ilişkiye dönüştürmek için kullanılabilir (Buss 2003). Alanyazında, Basson (2000) kadınların nasıl duygusal yakınlık, bağlanma, taahhüt alma, sevgi, şefkat, hoşgörü ve yakınlık gibi "yan ürünler”i elde etmek için cinsel ilişkiye girebildiklerini göstermiştir. Başka bir bakış açısından insanlar seksi "ilişkiyi korumak" için kullanabilmektedir (Buss ve Shackelford 1997). Bu ilk olarak eşi cinsel olarak memnun etme ve diş arayışa girmesinden uzak tutabilir. İkincisi, cinselliğin bu taktiksel kullanımı, belki de eşi evlilik dışı ilişkiye daha az "açık" hale getirerek, olası "yuva bozuculara" mesaj verebilir, böylece onların başka hedeflere yönelmesine neden olmaktadır (Schmitt ve Buss 2001, Schmitt 2004). Bir başka neden, sperm rekabeti literatüründen ortaya çıkmıştır (Baker ve Bellis 1995, Shackelford ve ark. 2005). Bu bakış açısından eşinin sadık olmama ihtimali olan erkek, rakip erkeğinin sperminin yerine kendininkini b1rakmak için seks yapmaktadır. Diğer cinsiyet olarak da kadın, eşinin spermini tüketerek "rakip kadını dölleme" ihtimalini azaltmaktadır. Bu hipotetik işlevlerin hiçbirinin bilinçli psikolojik mekanizmaları kullanması gerekmemektedir. Daha genel olarak seks ödenebilir bir kaynak olarak da görülebilir. Seks başka kaynaklar karşılığında değiş tokuş edilebilir. Fahişelik örneğinde olduğu gibi seksin para ile değiş tokuş edilmesi açık bir örnektir (Burley ve Symanski 1981).

Ergen ve gençlerin neden seks yaptığını bilmek onların cinsel davranışlarını anlamak açısından çok önemlidir (Dawson ve ark. 2008). Cooper ve arkadaşlarının (1998) 
gösterdiği gibi aynı görünen iki davranış farklı psikolojik amaçlara hizmet ediyorsa, farklı olarak değerlendirilmelidir. Ergen ve gençlerle yapılan çalışmalar seks için farklı nedenlerin daha az veya daha çok cinsel risk ile ilişkili olduğunu göstermiştir. Örneğin kendini daha iyi hissetmek (zevk) için yapılan seks, cinsel yolla bulaşan hastalıklar $(\mathrm{CBH})$, gebelik veya her ikisi için yüksek riskli cinsel davranışlarla ilişkilendirilmiştir. Bu yüksek riskli cinsel davranışlar ilk cinsel ilişki için daha küçük yaş, daha yüksek sıklıkta cinsel ilişki, daha çok sayıda cinsel eş, daha fazla yüksek riskli davranış (örneğin tek gecelik ilişki, yabancıyla ilişki), daha fazla plansız gebelik ve daha fazla $\mathrm{CBH}$ ile ilişkilidir (Cooper ve ark. 1998). Yakınlık amacıyla yapılan seks de daha sık sekse (Cooper ve ark. 1998, Browning ve ark. 2000) ve daha nadir ve istikrarsiz prezervatif kullanımı ile ilişkili bulunmuştur. Ancak İngiliz ergenler ilk cinsel ilişkiden önce kontraseptif kullanımını konuştuklarını (kız ergenler), ve ilk cinsel ilişkide kontrasepsiyon kullandıklarını (erkek ergenler) bildirmişlerdir (Stone ve Ingham 2002).

Daha önceki çalışmalar en azından dört etmenin seks yapma nedenlerindeki farkl1lıklarda etkili olabileceğini göstermiştir. İlk olarak seks rol stereotipileri göstermiştir ki erkekler kadınlardan daha çok zevk (Leigh, 1989, Browning ve ark. 2000, Meston ve Buss 2007) ve uyarilma (Eyre ve Millstein 1999, Meston ve Buss 2007); kadınlar ise daha çok aşk/yakınlık (Randolph ve Winstead 1988, Browning ve ark. 2000, Meston ve Buss 2007) nedeni ile seks yaptıklarını bildirmiştir. Ancak cinsiyetler arasındaki bu farkı desteklemeyen çalışmalar da vardır (Cooper ve ark. 1998). İkinci olarak yaşın da farklı nedenlerle seks yapmayı etkilediği bildirilmiştir. Yakın ilişki kurma sağlıklı ergen gelişiminin bir parçası olarak değerlendirilmekle birlikte (Weinstein ve Rosen 1991), yakınlık motivasyonu daha çok genç erişkinler (21 yaş ve üstü) tarafından bildirilmiştir (Cooper ve ark. 1998). Ergen kadınlarla yapılan uzunlamasına bir çalışmada ilk cinsel ilişki sırasında 17 yaş ve üstünde olan kadınların, o sırada yaşı daha küçük olanlara göre daha fazla aşı olma ve romantik hissetmeyi, seks yapma nedeni olarak bildirmişlerdir (Rosenthal ve ark. 2001). Üçüncü olarak, daha önce de belirtildiği gibi, ilişkinin durumu da seks yapma nedenlerindeki farklılıkları açıklayabilir. Diğer ilişki türlerinden farklı olarak özel ilişkisi olan genç erişkinler seks yapma nedeni olarak en fazla yakınlıkla ilişkili nedenleri, en az da başa çıkma ve eş veya partner onayını bildirmişlerdir (Cooper ve ark. 1998). Dördüncü olarak risk davranışının motivasyonel modelleri göstermiştir ki kişiler olumlu duygulanımı arttırmak veya olumsuz duygulanımı azaltmak için de bazı davranışları sergileyebilirler (Cooper ve ark. 1998, 2000).

Sigara, alkol ve madde kullanan ergenlerde yapılan çalışmada başa çıkma veya kaçınma nedenlerinin madde kullanımı kadar cinsel aktiviteyi de öngördüğünü göstermiştir. Toplum temelli bir ergen grubunda olumsuz duygulanımlarla başa çıkma amacıyla seks yapma çok sayıda seks partnerine sahip olma ile, partneri mutlu etme veya memnun etme amaciyla seks yapma ise daha etkisiz doğum kontrol yöntemi kullanma ve daha fazla plansız gebelik yaşama ile ilişkili bulunmuştur (Cooper ve ark. 1998). Ergen ve genç erişkinlerle yapılan başka çalışmalar da olumsuz duygulanımın yüksek riskli cinsel davranı̧̧ (örn. prezervatif kullanmama) ve istenmeyen sonuçlarla (örn. CBH) ile iliş̧kili bulunmuştur (Erbelding ve ark. 2001, Shrier ve ark. 2001). Depresyon veya anksiyete gibi olumsuz duygulanım yaşayan gençler, olumsuz duygulanımla başa çıkmak veya bu duygulanımdan kaçınmak için seks yapabilirler.

İnsanların neden seks yaptığını doğrudan araştıran birkaç çalışma bulunmaktadır (Leigh 1989, Meston ve Buss 2007). Bunların içinde en kapsamlılardan biri olan Mes- 
ton ve Buss'un (2007) yaptığ çalışma olup, iki kısımdan oluşmaktadır. Bu çalışmalar sonrası 142 maddeli, dört faktörlü (on üç alt-faktör) bir yapı elde edilmiştir. Bu dört ana faktörlerin bazıları- sevgi ve bağlılık, fiziksel haz, stres azaltma- daha önceki araştırmacılar tarafından da bildirilmiştir. Birçok motivasyonel gerekçenin seks ilişkisinin başlatılması veya sürdürülmesinde gerekçe olması, hem bireysel hem de toplumsal etmenlerin, hatta bu iki emenin birbirini etkilediği düşünülürse tüm etmenlerin ruh sağlı̆̆ı alanında çalışanlarının ilgi alanında kalması beklenilen bir durum olacaktır. Bu konuda temel niteliğinde bir dokümanın sağlanması ve geniş katılımlı kullanımı amacyyla Meston ve Buss'in Seks Nedenleri Ölçeği'nin (Why Have Sex? (YSEX?) Questionnaire) Türk örnekleminde geçerlik ve güvenirliğine bakılacaktır.

Tablo 1. En fazla 10 seks nedeni

\begin{tabular}{|c|c|c|c|c|c|}
\hline & Kadın & Ort. $\pm S S$ & & Erkek & Ort. \pm SS \\
\hline 18 & $\begin{array}{l}\text { Orgazmı yaşamak } \\
\text { istedim }\end{array}$ & $2.85 \pm 1.41$ & 25 & $\begin{array}{l}\text { Karşımdaki kişinin fiziksel } \\
\text { görünüşü beni heyecan- } \\
\text { landırmıştı }\end{array}$ & $3.14 \pm 1.22$ \\
\hline 17 & Saf zevk istedim & $2.52 \pm 1.40$ & 22 & $\begin{array}{l}\text { Karşımdaki kişi istek } \\
\text { uyandıran bir vücuda } \\
\text { sahipti }\end{array}$ & $3.11 \pm 1.32$ \\
\hline 14 & $\begin{array}{l}\text { Fiziksel olarak tatmin } \\
\text { olmak istedim }\end{array}$ & $2.50 \pm 1.30$ & 18 & Orgazmı yaşamak istedim & $3.10 \pm 1.46$ \\
\hline 20 & $\begin{array}{l}\text { Anın büyüsüne kapıl- } \\
\text { mıştım }\end{array}$ & $2.43 \pm 1.38$ & 14 & $\begin{array}{l}\text { Fiziksel olarak tatmin } \\
\text { olmak istedim }\end{array}$ & $3.02 \pm 1.42$ \\
\hline 6 & $\begin{array}{l}\text { Beni rahatlatacağını } \\
\text { düşündüm }\end{array}$ & $2.41 \pm 1.54$ & 17 & Saf zevk istedim & $3.01 \pm 1.30$ \\
\hline 13 & $\begin{array}{l}\text { lyi hissettireceğini } \\
\text { düşündüm }\end{array}$ & $2.41 \pm 1.25$ & 6 & $\begin{array}{l}\text { Beni rahatlatacağııı } \\
\text { düşündüm }\end{array}$ & $2.92 \pm 1.56$ \\
\hline 97 & $\begin{array}{l}\text { İlişkimi yoğunlaştırmak } \\
\text { istemiştim }\end{array}$ & $2.36 \pm 1.38$ & 15 & Çok azmışıım & $2.86 \pm 1.47$ \\
\hline 98 & $\begin{array}{l}\text { Duygusal yakınlık } \\
\text { arzulamıştım (örn } \\
\text { samimiyet) }\end{array}$ & $2.29 \pm 1.43$ & 19 & $\begin{array}{l}\text { Heyecanlı ve maceralı } \\
\text { olacağını düşündüm }\end{array}$ & $2.79 \pm 1.38$ \\
\hline 110 & $\begin{array}{l}\text { "seni özledim" demek } \\
\text { istemişstim }\end{array}$ & $2.29 \pm 1.43$ & 28 & $\begin{array}{l}\text { Fiziksel olarak karşı } \\
\text { konulamayacak kadar çok } \\
\text { çekiciydi }\end{array}$ & $2.74 \pm 1.16$ \\
\hline 24 & $\begin{array}{l}\text { Karşımdaki kişi güzel } \\
\text { kokuyordu }\end{array}$ & $2.26 \pm 1.46$ & 24 & $\begin{array}{l}\text { Karşımdaki kişi güzel } \\
\text { kokuyordu }\end{array}$ & $2.73 \pm 1.25$ \\
\hline
\end{tabular}

\section{Yöntem}

\section{Katılimcılar ve Işslem}

Bu çalışma Çukurova Üniversitesi'nde (ÇÜ) eğitim gören lisans öğrencileri ile İstanbul'da yaşayan sağlıklı bireyler arasında yürütüldü. Çalışmaya alınma koşulu olarak, genel sağlığı veya yaşamını etkileyebilecek bedensel hastalığ1, nörolojik ve psikiyatrik bozukluğu olmayan 18 yaşından büyük kişiler olmaları göz önünde bulunduruldu. $\mathrm{Bu}$ durumlarını değerlendirmek için ek bir görüşme ve araştırma yapılmadı, sadece kişilerin 
kendi sağlığı hakkındaki beyanları kabul edildi. Çalışmaya toplam 401 katılımcı dahil edildi.

Ölçek her iki dile hâkim bir araştırmacı tarafından Türkçeye çevrilmiş, profesyonel bir çevirmen tarafindan geri çevrilme işlemi yapılarak eksiklikler görülmüş ve ortak bir metin üzerinde anlaşılmıştır. Çalışma için Çukurova Üniversitesi Tıp Fakültesi Etik Kurulu'ndan onay alındı. Tüm katılımcılar çalışma hakkında bilgilendirildi ve katılmayı kabul edenlerden yazılı olurları alındı.

Tablo 2. En az 10 seks nedeni

\begin{tabular}{|c|c|c|c|c|c|}
\hline & Kadın & Ort. \pm SS & & Erkek & Ort. $\pm S S$ \\
\hline 58 & $\begin{array}{l}\text { Bana bunu yapmam karşılığında } \\
\text { uyuşturucu teklif etmişti }\end{array}$ & $1.00 \pm 0.0$ & 85 & $\begin{array}{l}\text { Beni pahalı bir akşam } \\
\text { yemeğine götürmüştü }\end{array}$ & $1.05 \pm 0.23$ \\
\hline 77 & $\begin{array}{l}\text { Rakibimin ilişkisini bozmak için } \\
\text { onun sevgilisi/eşi ile yattım }\end{array}$ & $1.02 \pm 0.19$ & 77 & $\begin{array}{l}\text { Rakibimin ilişkisini bozmak } \\
\text { için onun sevgilisi/eşi ile } \\
\text { yattım }\end{array}$ & $1.08 \pm 0.35$ \\
\hline 60 & $\begin{array}{l}\text { Kullanılmış veya aşağılanmı̧̧ } \\
\text { olmayı istemiştim }\end{array}$ & $1.03 \pm 0.26$ & $\begin{array}{l}14 \\
2\end{array}$ & $\begin{array}{l}\text { Yeni birini "tuzağa düşür- } \\
\text { meme" yardımı olacağını } \\
\text { düşünmmüştüm }\end{array}$ & $1.13 \pm 0.51$ \\
\hline 52 & $\begin{array}{l}\text { Biri bana bunu yapmam için para } \\
\text { teklif etmişti }\end{array}$ & $1.04 \pm 0.30$ & 80 & $\begin{array}{l}\text { Başka birisinin ilişkisini } \\
\text { bozmak istemiştim }\end{array}$ & $1.15 \pm 0.57$ \\
\hline 63 & $\begin{array}{l}\text { Arkadaşlarımdan daha çok seks } \\
\text { yapmış olmayı istemiştim }\end{array}$ & $1.04 \pm 0.28$ & 79 & $\begin{array}{l}\text { illgi duyduğum kişiyi } \\
\text { kıskandırmak istemiştim }\end{array}$ & $1.15 \pm 0.52$ \\
\hline 54 & Para kazanmak istemiştim & $1.05 \pm 0.26$ & 81 & $\begin{array}{l}\text { Düşmanıma acı çektirmek } \\
\text { istemiştim }\end{array}$ & $1.16 \pm 0.44$ \\
\hline 80 & $\begin{array}{l}\text { Başka birisinin ilişkisini bozmak } \\
\text { istemiştim. }\end{array}$ & $1.07 \pm 0.43$ & 69 & Birisine iyilik olsun diyeydi & $1.16 \pm 0.53$ \\
\hline 70 & Birisi bana meydan okumuştu & $1.07 \pm 0.41$ & 82 & $\begin{array}{l}\text { Başka bir şeyi yapmamı } \\
\text { engellemek istemiştim }\end{array}$ & $1.17 \pm 0.66$ \\
\hline 71 & $\begin{array}{l}\text { Arkadaşlarımı etkilemek istemiş- } \\
\text { tim }\end{array}$ & $1.07 \pm 0.41$ & 64 & $\begin{array}{l}\text { "kişiyi elde etmek için" bir } \\
\text { başkasılyla yarışııordum }\end{array}$ & $1.18 \pm 0.55$ \\
\hline 57 & $\begin{array}{l}\text { Bir klüp veya organizasyona } \\
\text { kabul edilmem için gerekliydi. }\end{array}$ & $1.08 \pm 0.36$ & 58 & $\begin{array}{l}\text { Bana bunu yapmam } \\
\text { karşılı̆ında uyuşturucu } \\
\text { teklif etmişti }\end{array}$ & $1.19 \pm 0.60$ \\
\hline
\end{tabular}

\section{Veri Toplama Araçları}

\section{Sosyodemografik Veri Toplama Formu}

Araştırmacılar tarafından oluşturulmuş, katılımcıların demografik özellikleri yanı sıra her iki cinsiyet için farklı olan cinsel öykülerinin alındığı yarı yapılandırılmış bir formdur.

\section{Seks Nedenleri Ölçeği (Why Have Sex? (YSEX?) Questionnaire -YSEX?)}

Meston ve Buss tarafından geliştirilmiştir. İlk kısımda cinsel ilişkiye girmek için 237 neden tanımlanmıştır. Bunlar günlük sıradan nedenlerden (ör."fiziksel haz yaşamak istedim”) ruhani nedenlere (ör.”tanrıya daha yakın olmak istedim”); özgecilikten (ör."kendini daha iyi hissetmesini istedim") intikam amacı gütmeye ("partnerime benim tarafımdan aldatılmı̧ hissettirmek için dönmek istedim”) diye ifade edilen farklılıklar 
içermektedir. İkinci kısımda katılımcılara $(\mathrm{N}=1.549) 237$ nedenden her birinin ne derecede cinsel ilişkiye girmelerini etkilediğini araştırmıştır. Bunların içinden 142 madde 4 ana faktör ve 13 alt faktör şeklinde temsil edildiği bir model oluşturulmuştur. Bunlar hiyerarşik bir taksonomi oluşturmaktadır. 1) Fiziksel Neden alt faktörleri "Stres Azaltma”, “Zevk”, "Fiziksel Uyarılma”, "Deneyim Arama”. 2) Amaç Elde Etme Nedeni alt faktörleri "Kaynaklar", "Sosyal Statü", "İntikam" ve "Fayda Sağlama”. 3) Duygusal Neden alt faktörleri "Sevgi ve Sahiplenilme" ve "Duyguların İfade Edilmesi”ni kapsar. 4) Sadakatsizlik Nedeni alt faktörleri "Özgüven Yükseltme”, "Görev/Baskı” ve "İlişkiyi Koruma"yı kapsar.

Tablo 3. Cinsiyetler arasındaki en fazla farklı olan 10 seks nedeni

\begin{tabular}{|c|c|c|c|c|c|}
\hline & & Kadın & Erkek & & \\
\hline & & Ort. \pm SS & Ort..ESS & $\mathbf{t}$ & $\mathbf{p}$ \\
\hline 7 & Sekse bağımlıyım & $1.30 \pm 0.70$ & $2.44 \pm 1.39$ & -10.77 & $<0.001$ \\
\hline 43 & Karşıma fırsat çıkmıştı, değerlendirdim & $1.31 \pm 0.80$ & $2.47 \pm 1.40$ & -10.46 & $<0.001$ \\
\hline 36 & $\begin{array}{l}\text { Başka biriyle (partnerim dışında) cinsel ilişkiye } \\
\text { girmenin nasıl birşey olduğunu görmek istedim }\end{array}$ & $1.16 \pm 0.53$ & $2.07 \pm 1.22$ & -10.05 & $<0.001$ \\
\hline 22 & $\begin{array}{l}\text { Karşımdaki kişi istek uyandıran bir vücuda } \\
\text { sahipti }\end{array}$ & $1.84 \pm 1.27$ & $3.11 \pm 1.32$ & -9.66 & $<0.001$ \\
\hline 45 & $\begin{array}{l}\text { Başka bir partnerle seks yapmanın daha iyi veya } \\
\text { farklı hissettirip hissettirmediğini görmek } \\
\text { istedim }\end{array}$ & $1.26 \pm 0.72$ & $2.16 \pm 1.22$ & -9.24 & $<0.001$ \\
\hline 29 & Açık saçık (baştan çıkarıı) kıyafetler giymişti & $1.32 \pm 0.84$ & $2.22 \pm 1.14$ & -9.01 & $<0.001$ \\
\hline 28 & $\begin{array}{l}\text { Fiziksel olarak karşı konulamayacak kadar çok } \\
\text { çekiciydi }\end{array}$ & $1.77 \pm 1.04$ & $2.74 \pm 1.16$ & -8.80 & $<0.001$ \\
\hline 44 & Bir fantaziyi yaşamak istedim & $1.70 \pm 1.10$ & $2.60 \pm 1.19$ & -7.82 & $<0.001$ \\
\hline 25 & $\begin{array}{l}\text { Karşımdaki kişinin fiziksel görünüuşü beni } \\
\text { heyecanlandırmıştı }\end{array}$ & $2.14 \pm 1.33$ & $3.14 \pm 1.22$ & -7.75 & $<0.001$ \\
\hline 26 & Onu çıplak gördüm ve karşı koyamadım & $1.62 \pm 1.16$ & $2.52 \pm 1.16$ & -7.72 & $<0.001$ \\
\hline
\end{tabular}

Tablo 4. YSEX? iç tutarlık incelemesi, her maddenin ölçeğe etkisi ve ölçeğin madde harici alfa değerleri

\begin{tabular}{|l|c|c|c|}
\hline & Madde-toplam ilişkisi & Madde silindiğinde alfa & Cronbach alfa \\
\hline YSEX? & $0.20-0.72$ & 0.97 & 0.97 \\
\hline Fiziksel & $0.48-0.73$ & 0.96 & 0.96 \\
\hline Amaç Edinme & $0.27-0.91$ & 0.97 & 0.97 \\
\hline Duygusal & $0.40-0.78$ & 0.93 & 0.93 \\
\hline Sadakatsizlik & $0.54-0.82$ & 0.96 & 0.96 \\
\hline
\end{tabular}

\section{Eysenck Kişilik Anketi Gözden Geçirilmiş-Kısaltılmış (EGA-GGK)}

Francis ve arkadaşları (1992), Eysenck Kişilik Anketi (Eysenck ve Eysenck 1975) ve aynı anketin kısa formunu (Eysenck ve ark. 1985) (48 madde) gözden geçirerek EKAGGK'yı oluşturmuştur. Anket, 24 madde olup kişiliği üç ana faktörde değerlendirmektedir: "Dışa Dönüklük", "Nörotisizm”, "Psikotisizm” (dördüncü faktör olarak, "Yalan Söyleme" alt ölçeği ile anketin uygulanması sırasındaki yanlılığı engellemek ve geçerliliği ile ilgili kontrol amaçlanmaktadır). 
Tablo 5. YSEX? faktör yapısı, madde dağılımı ve faktör yükleri

\begin{tabular}{|c|c|c|c|c|c|c|c|}
\hline \multicolumn{2}{|c|}{ Fiziksel neden } & \multicolumn{2}{|c|}{ Amaç elde etme } & \multicolumn{2}{|c|}{ Duygusal neden } & \multicolumn{2}{|c|}{ Sadakat } \\
\hline ysex1 & .57 & ysex46 & .64 & ysex5 & .49 & ysex 40 & .51 \\
\hline ysex2 & .72 & ysex47 & .62 & ysex23 & .52 & ysex91 & .43 \\
\hline ysex3 & .67 & ysex48 & .64 & ysex24 & .48 & ysex92 & .54 \\
\hline ysex4 & .50 & ysex49 & .77 & ysex31 & .37 & ysex95 & .55 \\
\hline ysex6 & .66 & ysex50 & .82 & ysex 55 & .48 & ysex104 & .50 \\
\hline ysex7 & .64 & ysex51 & .79 & ysex56 & .47 & ysex107 & .58 \\
\hline ysex8 & .63 & ysex52 & .77 & ysex83 & .57 & ysex 112 & .54 \\
\hline ysex9 & .67 & ysex53 & .69 & ysex 84 & .61 & ysex113 & .58 \\
\hline ysex10 & .62 & ysex54 & .81 & ysex93 & .64 & ysex114 & .58 \\
\hline ysex11 & .43 & ysex57 & .73 & ysex94 & .65 & ysex116 & .69 \\
\hline ysex12 & .68 & ysex58 & .67 & ysex96 & .63 & ysex117 & .66 \\
\hline ysex13 & .70 & ysex59 & .63 & ysex97 & .72 & ysex118 & .47 \\
\hline ysex14 & .62 & ysex60 & .56 & ysex 98 & .52 & ysex121 & .62 \\
\hline ysex15 & .72 & ysex61 & .62 & ysex99 & .62 & ysex 122 & .60 \\
\hline ysex16 & .64 & ysex62 & .59 & ysex100 & .41 & ysex123 & .62 \\
\hline ysex17 & .51 & ysex63 & .63 & ysex101 & .73 & ysex124 & .67 \\
\hline ysex18 & .51 & ysex64 & .83 & ysex102 & .42 & ysex125 & .73 \\
\hline ysex19 & .68 & ysex65 & .80 & ysex109 & .66 & ysex127 & .64 \\
\hline ysex20 & .48 & ysex66 & .69 & ysex110 & .59 & ysex 128 & .53 \\
\hline ysex21 & .54 & ysex67 & .62 & ysex111 & .54 & ysex129 & .67 \\
\hline$y$ yex22 & .68 & ysex68 & .83 & ysex115 & .58 & ysex130 & .65 \\
\hline ysex25 & .59 & ysex69 & .83 & ysex120 & .57 & ysex131 & .65 \\
\hline ysex26 & .61 & ysex70 & .82 & & & ysex132 & .66 \\
\hline ysex27 & .49 & ysex71 & .52 & & & ysex133 & .62 \\
\hline ysex28 & .61 & ysex72 & .65 & & & ysex134 & .73 \\
\hline ysex29 & .60 & ysex73 & .35 & & & ysex135 & .76 \\
\hline ysex30 & .62 & ysex74 & .76 & & & ysex136 & .66 \\
\hline ysex32 & .54 & ysex75 & .68 & & & ysex137 & .76 \\
\hline ysex33 & .48 & ysex76 & .86 & & & ysex138 & .73 \\
\hline ysex34 & .62 & ysex77 & .66 & & & ysex139 & .62 \\
\hline ysex35 & .49 & ysex78 & .54 & & & ysex140 & .61 \\
\hline ysex36 & .53 & ysex79 & .77 & & & ysex141 & .46 \\
\hline ysex37 & .69 & ysex80 & .76 & & & & \\
\hline ysex38 & .66 & ysex81 & .80 & & & & \\
\hline ysex39 & .58 & ysex82 & .78 & & & & \\
\hline ysex41 & .53 & ysex85 & .56 & & & & \\
\hline ysex42 & .61 & ysex86 & .54 & & & & \\
\hline ysex43 & .71 & ysex87 & .58 & & & & \\
\hline ysex44 & .54 & ysex88 & .42 & & & & \\
\hline ysex45 & .67 & ysex89 & .62 & & & & \\
\hline ysex103 & .37 & ysex90 & .51 & & & & \\
\hline & & ysex105 & .47 & & & & \\
\hline & & ysex106 & .69 & & & & \\
\hline & & ysex108 & .55 & & & & \\
\hline & & ysex119 & .54 & & & & \\
\hline & & ysex126 & .55 & & & & \\
\hline & & ysex142 & .64 & & & & \\
\hline
\end{tabular}


Her faktörün altı madde ile değerlendirildiği bu ankette, katılımcıdan 24 soruya Evet (1) / Hayır (0) formatıyla (ters maddeler dikkate alınarak) yanıt vermesi istenir. Her kişilik özelliği için alınabilecek puan 0-6 arasında değişmektedir. Türkçe uyarlaması yapılmışır (Karancı ve ark. 2007).

Tablo 6. YSEX? ölçeğinin EKA-GGK ölçeği ile ilişkisi

\begin{tabular}{|l|c|c|c|c|c|}
\hline & YSEX? & Fiziksel neden & Amaç elde etme & Duygusal neden & Sadakat \\
\cline { 2 - 6 } & $\mathbf{r}$ & $\mathbf{r}$ & $\mathbf{r}$ & $\mathbf{r}$ & $\mathbf{r}$ \\
\hline Dişa dönüklük & -0.03 & 0.02 & 0.03 & -0.05 & $-0.10^{*}$ \\
\hline Yalan & $-0.16^{* *}$ & $-0.35^{* *}$ & 0.02 & -0.09 & 0.03 \\
\hline Nörotisizm & 0.20 & $0.25^{* *}$ & -0.04 & 0.09 & $0.24^{* *}$ \\
\hline Psikotizm & 0.04 & -0.05 & $-0.20^{* *}$ & 0.01 & 0.01 \\
\hline
\end{tabular}

${ }^{*} \mathrm{p}<0.05,{ }^{* *} \mathrm{p}<0.01$; EKA-GGK: Eysenck Kişilik Anketi Gözden geçirilmiş-Kısaltılmış

\section{İstatistiksel Analiz}

Ölçeğin geçerlik ve güvenirlik araştırması için 401 sağlıklı birey alındı. Sosyodemografik verilerin karşılaştırmalarında ölçümsel veriler student $t$ testi, kategorik veriler ki-kare testi ile değerlendirildi. İç tutarlığı Cronbach's alfa testi ile incelendi. Madde-toplam ilişki analizi yapıldı. Geçerliğin ölçümünde ise faktöriyel yapısına ve ölçüt bağıntılı geçerliğine bakıldı. Açımlayıcı faktör analizine göre, Temel Bileşenler Analizi uygulandı. Varimax döndürme işlemi yapıldı. Ölçüt bağıntılı geçerlik analizi için EGA-KKÖ ölçeği arasındaki bağıntıları incelendi. Araştırma verilerin değerlendirilmesinde SPSS 9.0 istatistik programı kullanılmıştır.

\section{Bulgular}

Araştırmada yer alan grupların sosyodemografik özellikleri incelendiğinde, kontrol grubunun 234'ü kadın olup grubun \%58.4'ini oluşturmaktadır. Yaş dağılımı 18 ve 66 arasında değişmekte olup ortalama yaş $23.45 \pm 9.75$ 'dir. Eğitim durumu olarak \%0.7'si okuma-yazması yok, \%11'i ilköğretim, \%26.9'u lise, \%55.4'ü lisans ve \%6.0' s1 yüksek lisans mezunu olduğu görüldü. En fazla (Tablo 1) ve en az (Tablo 2) 10 seks nedeni her iki cinsiyet için ayrı olarak gösterildi. Ayrıca cinsiyetler arası en fazla farklılığın olduğu on seks nedeni Tablo 3'de gösterildi. Ölçeğin iç tutarlık, madde toplam ilişkisi ve madde harici alfa değerleri Tablo 4'de gösterildi. İç tutarlığı çok iyi seviyede olarak Cronbach alfa değeri 0.97 olduğu görüldü. Her bir madde tek tek ele alındığında maddetoplam puan ilişkisine bakıldığında; yüksek düzeyde ilişki gösterdiği saptandı.

Ölçeğin faktör yapısının incelendiği açımlayıcı faktör analizine göre tüm maddelerin faktör analizine girebileceği belirlendikten sonra orijinal çalışmaya uygun olacak şekilde dört faktör altına yüklendiği görüldü. Aynı zamanda faktör sayısının belirlenmesinde Scree plot grafiğinden yararlanıldı. Dört faktörün varyansın \%51.67’sini açıkladığ görüldü. Varimax yöntemi ile döndürülmüşs sonuçları Tablo 5 'de gösterildi. Ölçüt bağıntılı geçerliği için EGA-GGK ile ilişkisi Tablo 6'de gösterildi.

\section{Tartı̧̧ma}

Bu çalışmada Seks Nedenleri Ölçeği'nin geçerlik ve güvenirliği çalışıldı. İç tutarlığı, 
madde toplam ilişkisi, faktöriyel yapısı ve ölçüt bağıntılı geçerliği sonuçlarına bakılarak Türk örneklemi için istatistiksel olarak iyi düzeyde güvenirlik ve geçerli olduğu görüldü.

Güvenirlik analizi olarak Seks Nedenleri Ölçeği'nin iç tutarlık analizine ve madde toplam ilişkilerine bakıldı. İç tutarlık analizi için Cronbach alfa katsayılarına bakıldığında, bu değerin 0.97 seviyesinde olduğu saptandı. Orijinal çalışmada güvenirlik analizleri yapılmadığı için karşılaştırma imkanı bulunmamasına rağmen bu değerlerin iyi seviyede bulunması bu ölçeğin güvenirliği için önemli bir bulgu olacaktır. Madde toplam ilişkisine bakıldığında tüm maddeler ölçeğin ölçme gücüne katkıda bulunmaktadır.

Örneklemde her iki cinsiyet için en fazla ve en az 10 seks nedenlerine bakıldı. Her iki cinsiyet için seks nedenlerinin birbirinden farklılaştığı görüldü. Her cinsiyete özgü bir neden listesi cinsiyetler arası farklılığı göstermesi bu ölçeğin farklılığı ortaya koymayı sağladığını desteklemektedir.

Ölçeğin geçerliği için yürütülen yöntemlerden biri olarak faktöriyel yapısına bakıldığında, dört faktörlü yapıyı gösterdiği ve ilgili faktöre düşen maddelerin orijinal çalışma ile aynı olduğu görüldü. Bu nedenle madde dağılımı olarak aynı faktörle temsil edilen her bir boyut için orijinal çalışmada kullanılan isimler verilmesi uygun görüldü. Orijinal çalışmadan farklı olarak Fiziksel Neden boyutunda yer alan 5., 23., 24. ve 31. maddenin Duygusal Neden boyutuna; 40. maddenin Sadakatsizlik boyutuna yüklendiği görüldü. Amaç Elde Etme boyutunda yer alan 55., 56., 83. ve 84. maddenin Duygusal Neden boyutuna; 91. maddenin Sadakatsizlik boyutuna düştüğü görüldü. Duygusal Neden boyutunda 105., 106. ve 108. maddelerin Amaç Elde Etme boyutuna; 104. ve 107. maddelerin Sadakatsizlik boyutuna yüklendiği görüldü. Sadakatsizlik boyutunda 115. ve 120. maddelerin Duygusal Neden boyutuna; 119. ve 142. maddelerin de Amaç Elde Etme boyutuna yüklendiği görüldü. Maddelerin farklı faktörler altında yer alması ölçeğin Türk örneklemlerde yürütülen çalışmalarında bu maddelerden gelen yanıtların değerlendirilmesinde, kültürler arası farklılığa dikkat edilmesi gerekebilir.

Benzer ölçek geçerliği için orijinal çalışmada tercih edilen bir ölçek olarak, Eysenck Kişilik Anketi ölçeği verildi. Çalışmamızda toplam puan Yalan alt ölçeği ile negatif yönde ilişkili bulundu. Fiziksel Neden alt ölçeği, Yalan ile ters; Nörotism ile doğrusal ilişkili bulundu. Amaç Elde Etme alt ölçeği Psikotizm alt ölçeği ile ters yönde ilişkili olarak bulundu. Duygusal Neden alt ölçeği kişilik boyutlarından hiçbiriyle ilişkili bulunmazken, Sadakat alt boyutunu, Dişadönüklük alt ölçeği ile ters, Nörotisizm ile doğrusal olarak ilişkili olarak bulduk.

Sonuç olarak, bulgularımız YSEX? ölçeğinin Türk toplumunda geçerli ve güvenilir olduğunu göstermektedir.

\section{Kaynaklar}

Baker RR, Bellis MA (1995) Human Sperm Competition. London, Chapman \& Hall.

Basson R (2000) The female sexual response: a different model. J Sex Marital Ther, 26:51-65.

Browning JR, Hatfield E, Kessler D, Levine T (2000) Sexual motives, gender, and sexual behavior. Arch Sex Behav, 29:135-153.

Burley N, Symanski R (1981) Women without: an evolutionary and cross-cultural perspective on prostitution. In The Immoral Landscape: Female Prostitution in Western Societies (Ed IR Symanski):239-274. Toronto, Butterworth.

Buss DM (2003) The Evolution of Desire: Strategies of Human Mating. New York, Basic Books.

Buss DM, Schmitt DP (1993) Sexual strategies theory: an evolutionary perspective on human mating. Psychol Rev, 100:204-232.

Buss DM, Shackelford TK (1997) From vigilance to violence: mate retention tactics in married couples. J Pers Soc Psychol, 72:346361. 
Cooper ML, Agocha VB, Sheldon MS (2000) A motivational perspective on risky behaviors: the role of personality and affect regulatory processes. J Pers, 68:1059-1088.

Cooper ML, Shapiro CM, Powers AM (1988) Motivations for sex and risky sexual behavior among adolescents and young adults: a functional perspective. J Pers Soc Psychol. 75:1528-1558.

Erbelding EJ, Hummel B, Hogan T, Zenilman J (2001) High rates of depressive symptoms in STD clinic patients. Sex Transm Dis, 28:281-284

Eyre SL, Millstein SG (1999) What leads to sex? adolescent preferred partners and reasons for sex. J Res Adolesc, 9:277-307.

Eysenck HJ, Eysenck SB (1975) Manual of the Eysenck Personality Questionnaire (adult and junior). London, Hodder Stoughton.

Eysenck SBG, Eysenck HJ, Barrett P (1985) A revised version of the psychoticism scale. Pers Individ Dif, 6:21-29.

Francis L, Brown LB, Philipchalk R (1992) The development of an abbreviated form of the Revised Eysenck Personality Questionnaire (EPQR-A): its use among students in England, Canada, the USA and Australia. Pers Individ Dif, 13:443-449.

Gangestad SW, Simpson JA (2000) The evolution of human mating: trade-offs and strategic pluralism. Behav Brain Sci, 23:675687.

Greiling H, Buss DM (2000) Women's sexual strategies: the hidden dimension of extra-pair mating. Pers Individ Dif, 28:929-963.

Hill CA, Preston LK (1996) Individual differences in the experience of sexual motivation: Theory and measurement of dispositional sexual motives. J Sex Res, 33:27-45.

Karanc N, Dirik G, Yorulmaz 0 (2007) Reliability and validity studies of Turkish translation of Eysenck Personality Questionnaire Revised-Abbreviated. Turk Psikiyatri Derg, 18:254-261.

Leigh BC (1989) Reasons for having and avoiding sex: Gender, sexual orientation, and relationship to sexual behavior. J Sex Res, 26:199-209.

Meston CM, Buss DM (2007) Why humans have sex. Arch Sex Behav, 2007;36:477-507

Randolph BJ1, Winstead B (1988) Sexual decision making and object relations theory. Arch Sex Behav, 17:389-409.

Rosenthal SL, Von Ranson KM, Cotton S, Biro FM, Mills L, Succop PA (2001) Sexual initiation: predictors and developmental trends. Sex Transm Dis, 28:527-532.

Schmitt DP (2004) Patterns and universals of mate poaching across 53 nations: the effects of sex, culture, and personality on romantically attracting another person. J Pers Soc Psychol, 86:560-584.

Schmitt DP, Buss DM (2001) Human mate poaching: tactics and temptations for infiltrating existing relationships. J Pers Soc Psychol, 80:894-917.

Shackelford TK, Pound N, Goetz AT, LaMunyon CW (2005) Female infidelity and sperm competition. In The Handbook of Evolutionary Psychology (Ed DM Buss):372-393. New York, Wiley.

Shrier LA, Harris SK, Sternberg M, Beardslee WR (2001) Associations of depression, self-esteem, and substance use with sexual risk among adolescents. Prev Med, 33:179-189.

Stone N, Ingham R (2002) Factors affecting British teenagers' contraceptive use at first intercourse: the importance of partner communication. Perspect Sex Reprod Health, 34:191-197.

Symons D (1979). The Evolution of Human Sexuality. New York, Oxford University Press.

Weinstein E, Rosen E (1991) The development of adolescent sexual intimacy: implications for counseling. Adolescence, 26:331339.

Sevilay Özcan, Adana Ruh ve Sinir Hastalıkları Hastanesi, Adana.; Hüseyin Güleç, Erenköy Ruh ve Sinir Hastalıkları Hastanesi, İstanbul; Jülide Demir, Erenköy Ruh ve Sinir Hast. Hastanesi, İstanbul; Lut Tamam, Çukurova Üniversitesi, Adana; Ayçe Soydan, Adana Ruh ve Sinir Hastalıkları Hastanesi, Adana.

Yazışma Adresi/Correspondence: Sevilay Özcan, Adana Ruh ve Sinir Hastalıkları Hastanesi, Adana, Turkey.

E-mail: ozcansevilay@yahoo.com

Bu makale ile ilgili herhangi bir çıkar çatışması bildirilmemiştir · No conflict of interest is declared related to this article

Çevrimiçi adresi / Available online: www.cappsy.org/archives/vol9/no1/

Geliş tarihi/Submission date: 1 Mart/March 1, 2016 · Kabul Tarihi/Accepted 22 Mayıs/May 22, 2016 


\section{Seks Nedenleri Ölçeği (YSEX?)}

İnsanlar çeşitli nedenlerle cinsel ilişkiye (örn. cinsel yakınlaşma) girerler. Aşağıda bu nedenlerden bazılarından oluşan bir liste bulunmaktadır. Lütfen, bunlardan her birinin ne sıklıkta sizin cinsel ilişkiye girmenizin nedeni olduğunu belirtin. Örneğin, sevişmelerinizin yarısında sebebiniz sıkılmış olmanız ise 4. sorunun cevabı olarak "3" ü yuvarlak içine almanız gerekir. Eğer geçmişte cinsel ilişki yaşamadıysanız, bu soruları aşağıdaki nedenlerden hangisinin gelecekte sizi cinsel ilişkiye daha fazla yönlendireceğini düşündüğünüzü belirtmek için kullanın.

Geçmişte cinsel ilişkiye girdim çünkü.....

\begin{tabular}{|l|l|l|l|l|}
\hline 1 & \multicolumn{1}{|c|}{2} & \multicolumn{1}{c|}{3} & \multicolumn{1}{c|}{4} & \multicolumn{1}{c|}{5} \\
\hline $\begin{array}{l}\text { Cinsel ilişkilerimin } \\
\text { hiç birinde }\end{array}$ & $\begin{array}{l}\text { Cinsel ilişkilerimin } \\
\text { az bir kısmında }\end{array}$ & $\begin{array}{l}\text { Cinsel ilişkilerimin } \\
\text { yarısında }\end{array}$ & $\begin{array}{l}\text { Cinsel iliş̧ierimin } \\
\text { çoğunda }\end{array}$ & $\begin{array}{l}\text { Cinsel ilişkilerimin } \\
\text { hepsinde }\end{array}$ \\
\hline
\end{tabular}

\begin{tabular}{|c|c|c|c|c|c|}
\hline \multirow{2}{*}{$\begin{array}{l}\text { 1. Hayal kırıklığına uğramıştım ve rahatlamaya ihtiyacım vardı. } \\
\end{array}$} & 1 & 2 & 3 & 4 & 5 \\
\hline & & & & & \\
\hline 2. Kaygımı/stresimi azaltmak istedim. & & & & & \\
\hline 3. Gerginliğimi azaltmak istedim. & & & & & \\
\hline 4. Sıkılmıştım. & & & & & \\
\hline 5. İyi bir egzersiz olacağını düşündüm. & & & & & \\
\hline 6. Beni rahatlatacağını düşündüm. & & & & & \\
\hline 7. Sekse bağımlıyım. & & & & & \\
\hline 8. Cinselliği aklımdan çıkartıp diğer konulara odaklanmak istedim. & & & & & \\
\hline 9. Ben bir seks bağımlısıyım. & & & & & \\
\hline 10. Bana kendimi sağlıklı hissettireceğini düşündüm. & & & & & \\
\hline 11. Bir süredir sevişmemiştim. & & & & & \\
\hline $\begin{array}{l}\text { 12. Yapmak için yoğun istek duyduğum bir şeyde başarılı olmak } \\
\text { istedim. }\end{array}$ & & & & & \\
\hline 13. İyi hissettireceğini düşündüm. & & & & & \\
\hline 14. Fiziksel olarak tatmin olmak istedim. & & & & & \\
\hline 15. Çok azmıştım. & & & & & \\
\hline 16. Eğlenceli olacağını düşündüm. & & & & & \\
\hline 17. Saf zevk istedim. & & & & & \\
\hline 18. Orgazmı yaşamak istedim. & & & & & \\
\hline 19. Heyecanlı ve maceralı olacağını düşündüm. & & & & & \\
\hline 20. Anın büyüsüne kapılmıştım. & & & & & \\
\hline 21. Karşımdaki kişinin çekici bir yüzü vardı. & & & & & \\
\hline 22. Karşımdaki kişi istek uyandıran bir vücuda sahipti. & & & & & \\
\hline 23. Karşımdaki kişinin güzel gözleri vardı. & & & & & \\
\hline 24. Karşımdaki kişi güzel kokuyordu. & & & & & \\
\hline 25. Karşımdaki kişinin fiziksel görünüşü beni heyecanlandırmıştı. & & & & & \\
\hline 26. Onu çıplak gördüm ve karşı koyamadım. & & & & & \\
\hline
\end{tabular}




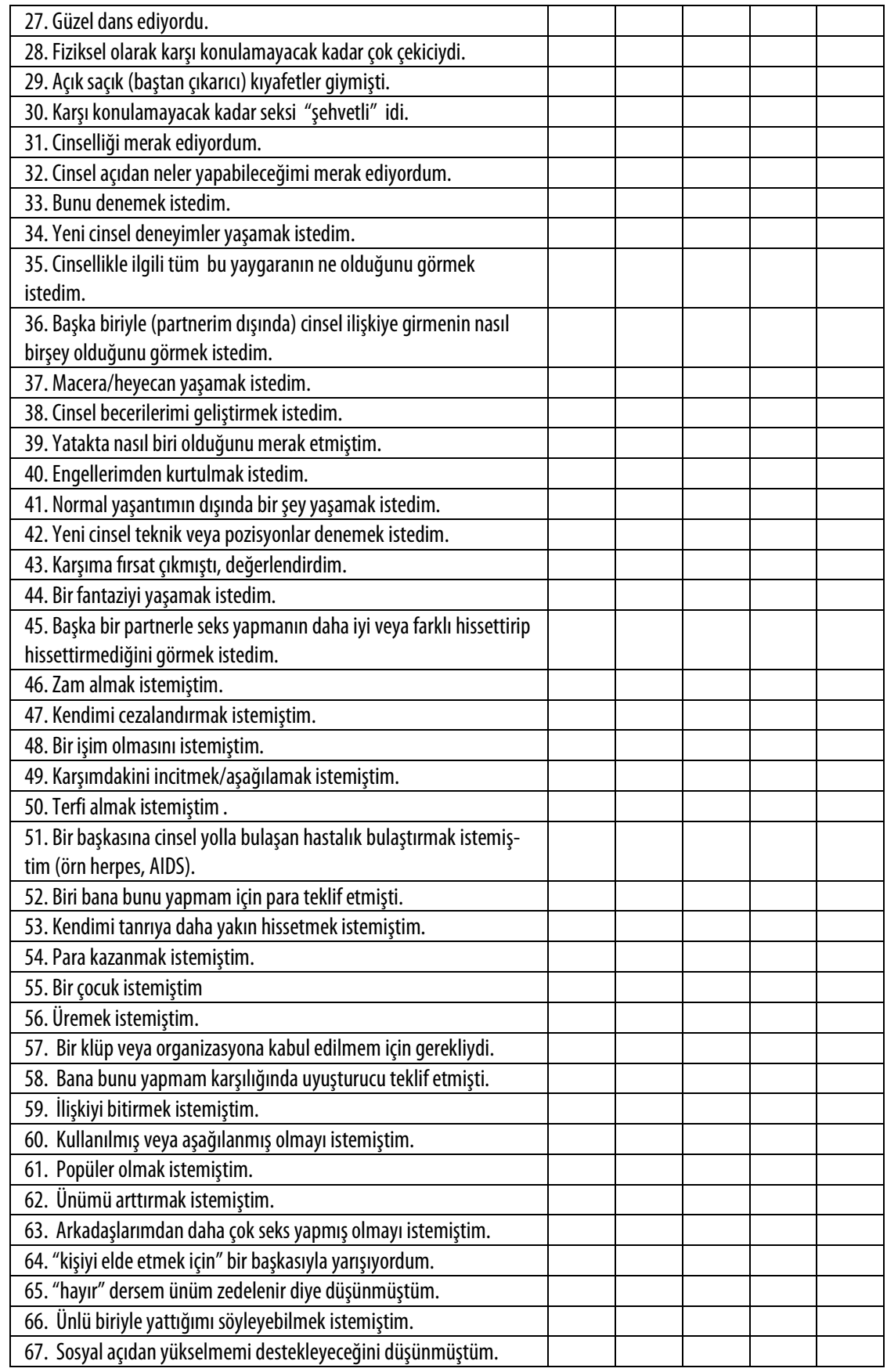




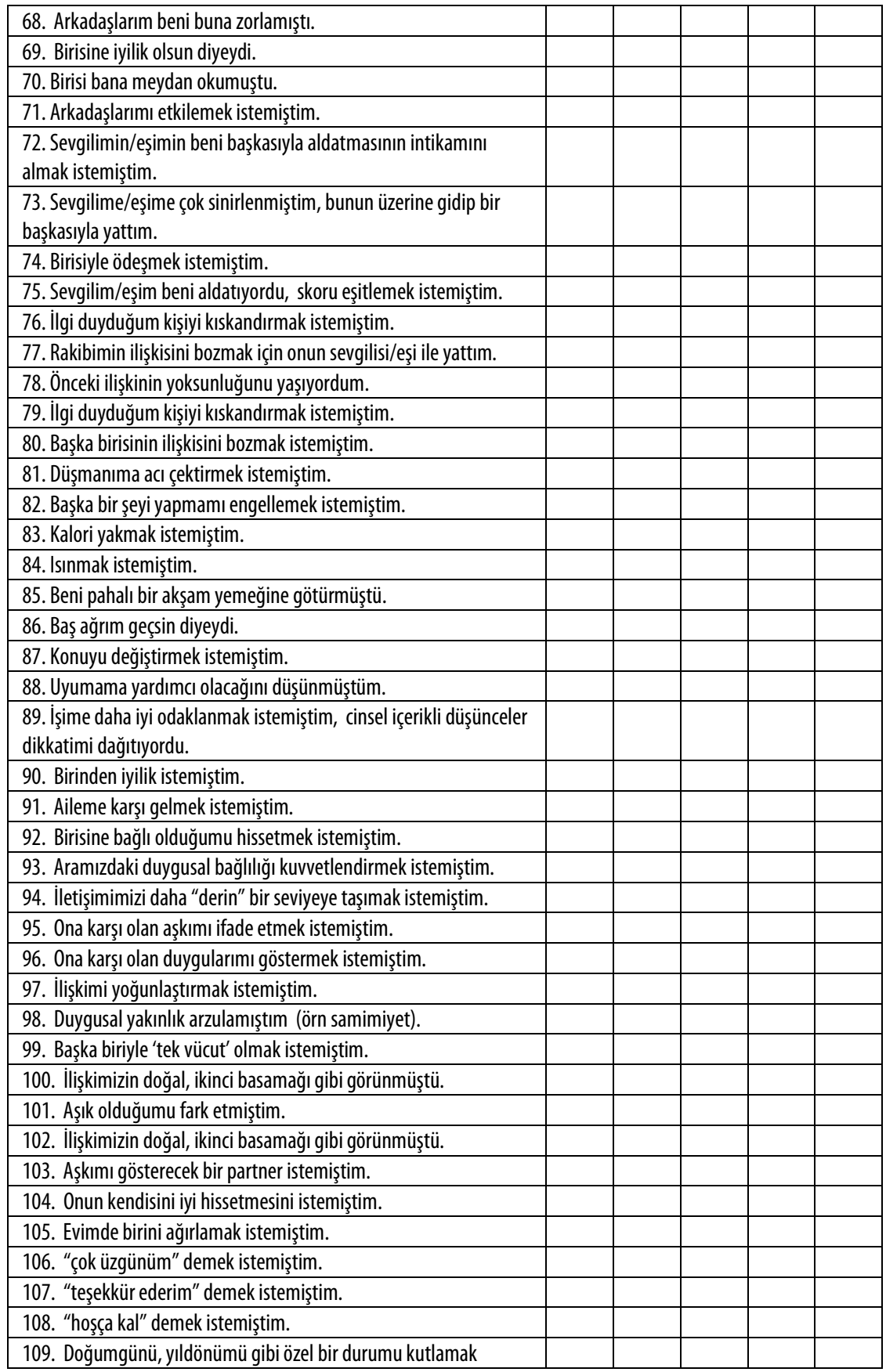




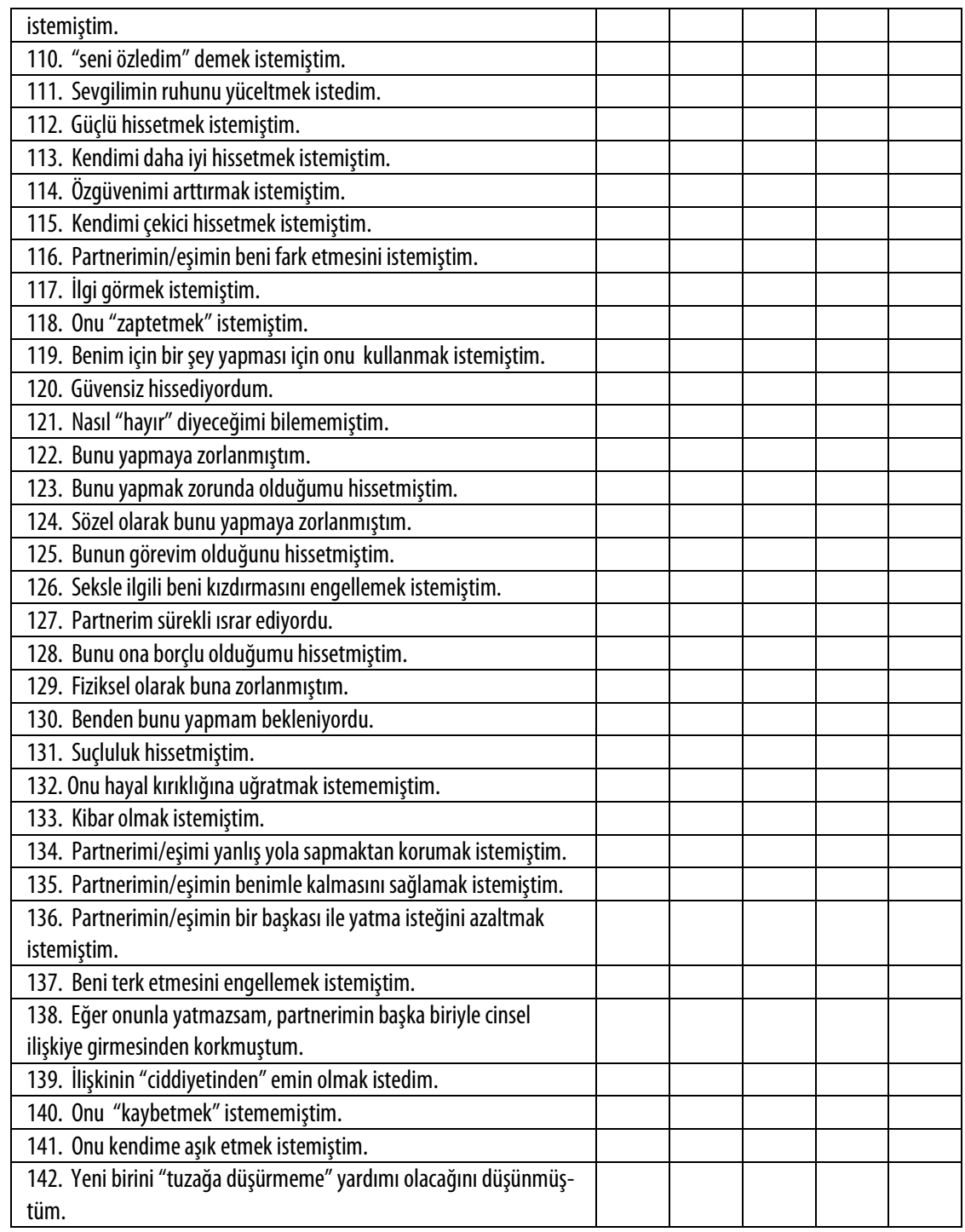

